\title{
Influence of Partial Replacement of $\mathrm{NaCl}$ with $\mathrm{KCl}$ on Formation of Volatile Compounds in Jinhua Ham during Processing
}

\author{
Yingyang Zhang', Haizhou Wu, Jing Tang, Mingming Huang, Jianying Zhao, and Jianhao Zhang* \\ National Center of Meat Quality and Safety Control, Synergetic Innovation Center of Food Safety and Nutrition, \\ College of Food Science and Technology, Nanjing Agricultural University, Nanjing, Jiangsu Province, 210095, China \\ ${ }^{1}$ School of Food Science and Technology, Changzhou University, Changzhou, Jiangsu Province, 213164, China
}

\author{
Received July 5, 2015 \\ Revised October 1, 2015 \\ Accepted November 7, 2015 \\ Published online April 30, 2016 \\ *Corresponding Author \\ Tel: $+86-25-84399096$ \\ Fax: +86-25-84399096 \\ E-mail: jianhao_zhang@163.com \\ pISSN 1226-7708 \\ eISSN 2092-6456 \\ (c) KoSFoST and Springer 2016
}

\begin{abstract}
The influence of partial replacement of $\mathrm{NaCl}$ with $\mathrm{KCl}$ on formation of volatile compounds during Jinhua ham processing was evaluated using GC/MS system. Jinhua ham was treated with either $100 \% \mathrm{NaCl}$ (I) or $60 \% \mathrm{NaCl}$ and $40 \% \mathrm{KCl}$ (II). Formation of volatile compounds increased in Jinhua hams during processing for both salt formulations, particularly at the end of the salting period. There were differences in volatile compound formation between formulations I and II after 45 days of processing. Contents of lipid-derived volatiles (hexanal) and Strecker aldehydes (2-methylbutanal and 3methylbutanal) were higher in Jinhua hams treated with formulation II after 45 days of processing. Partial salt replacement of $\mathrm{NaCl}$ with $\mathrm{KCl}$ changed formation of volatile compounds in Jinhua hams and may have affected the flavor of finished products.
\end{abstract}

Keywords: ham, $\mathrm{NaCl}$, replacement, $\mathrm{KCl}$, flavor

\section{Introduction}

Dry-cured ham is a traditionally-cured meat product that is popular worldwide (1) and is well-known for flavor. Jinhua ham is a typical dry-cured ham produced in China with a unique flavor, a high sodium chloride content, and have an important impact on local economies. Sodium chloride, an essential curing agent for manufacture of cured meat products, preserves food quality, enhances food flavor, and provides the essential nutrient sodium (2). However, too much sodium can cause high blood pressure and many other human health problems (3). Dry-cured ham is a not recommended for hypertensive consumers due to a high sodium content of $>5 \%$. Consequently, different approaches have been used to reduce sodium levels in dry-cured hams for targeting of healthy diet markets, including reduction of the salting time, addition of less $\mathrm{NaCl}$, and total or partial replacement of sodium with other salts, such as, $\mathrm{KCl}(2)$.

Development of salt substitutes for use with dry-fermented sausages and dry-cured ham has been studied (4), especially use of $\mathrm{KCl}$ to replace $\mathrm{NaCl}$. Replacement of $\mathrm{NaCl}$ with a high level of $\mathrm{KCl}$ of $>40 \%$ affected the sensory characteristics of meat (5).

There is a close relationship in meat products between sensory quality and formation of volatile compounds. Two different pathways are responsible for formation of volatile compounds that influence dry-cured ham flavors during processing. The first pathway involves enzymatic reactions, including both proteolysis and lipolysis, and the second involves chemical reactions, including lipid oxidation and Maillard and Strecker reactions (6). Enzymatic proteolysis contributes directly to flavor via formation of peptides and free amino acids, which are considered as flavor precursors and are involved in Maillard and Strecker reactions (7). Non-enzymatic lipid oxidation leads to formation of abundant volatile compounds in dry-cured ham via peroxidation products of unsaturated fatty acids (8). Effects of temperature on proteolysis, lipolysis, and flavor of Jinhua ham have been studied (9). However, the influence of replacing $\mathrm{NaCl}$ with $\mathrm{KCl}$ on generation of volatile compounds in Jinhua ham during processing remains unknown.

The objective of this study was evaluation of the influence of partial replacement of $\mathrm{NaCl}$ with $\mathrm{KCl}$ on formation of volatile compounds in Jinhua ham during processing. Results from this study should be useful for the processed ham industry for development of new ham products for a healthy diet without sacrificing traditional ham flavor.

\section{Materials and Methods}

Jinhua ham processing Jinhua ham processing was carried out at the Academy of Agricultural Sciences, Jiangsu Province, China in June of 2014. Forty-five green hams (raw ham) were purchased from Zhejiang Provincial Food Company (Hangzhou, Zhejiang Province, 
China) of 6.8-7.8 kg each from Taihux Durocx York crossbred pigs weighing 90 to $110 \mathrm{~kg}$. Five hams were used for green ham measurements on day 1 . The other 40 hams were randomly divided into 2 groups and subjected to a salting process for Jinhua hams (10). Hams were either salted with formulation I for control hams of $100 \%$ $\mathrm{NaCl}$, or formulation II for treatment hams of $60 \% \mathrm{NaCl}$ and $40 \% \mathrm{KCl}$. The total amount of salt was $6.5 \%(\mathrm{w} / \mathrm{w})$ of the ham weight. The 60:40 ratio was used based on a report of Wu et al. (11) and preliminary experiments. Processing conditions reported by Zhang et al. (10) were used.

Salting was considered complete when no salt crystals were observed on the ham surface. During salting, hams were piled and placed in a chamber at $4 \pm 2^{\circ} \mathrm{C}$ and $85 \%$ relative humidity for 45 days during which piled hams were turned over 15 times. After salting, hams were soaked in water for $24 \mathrm{~h}$, brushed, and dried for 3 days under the sun before the dry ripening process of aging in a loft chamber for 100 days with automatic temperature and humidity control. Mean values and ranges of temperature and relative humidity during dry-ripening are shown in Table 1.

Product sampling Both semimembranosus muscle (SM) and biceps femoris (BF) muscle (100 g) were sampled randomly from 5 hams from each formulation. Muscle samples were vacuum packed and stored at $40^{\circ} \mathrm{C}$ in freezer (BD-226W; Haier Company, Qingdao, China) prior to volatile analysis. Sampling times included green ham on day 1 of processing, at the end of salting, after 30 days of dry-ripening, after 60 days of dry-ripening, and after 100 days of dry-ripening.

\section{Analysis of volatile compounds}

Extraction: Jinhua ham volatile compounds formed during processing were extracted using an Eclipse 4660 purge and trap (PT) sample concentrator with a 4551A auto-sampler (OI Analytical Company, College Station, TX), a \#10 trap filled with tenax silica gel charcoal sorbent (OI Analytical), and a $40 \mathrm{~mL}$ purge vial (12). The PT system was operated with $3.5 \mathrm{~g}$ of minced ham in a PT vial at $40^{\circ} \mathrm{C}$ for $30 \mathrm{~min}$ using a purge gas of high purity nitrogen at a flow rate of $40 \mathrm{~mL} / \mathrm{min}$ at $60^{\circ} \mathrm{C}$ for $13 \mathrm{~min}$. Tenax silica gel charcoal sorbent heated to $220^{\circ} \mathrm{C}$ with helium desorption for $2 \mathrm{~min}$ and direct transfer to a Thermo Finnigan GC/MS system (Thermo Electron Corporation, Waltham, MA, USA) followed. The trap was baked at $240^{\circ} \mathrm{C}$ for 30 min every time before use for removal of potential residues and/or contaminants. Chromatographic method: Volatile compounds were identified using the method described by Huan et al. (13) with slight modification. Volatiles compounds were transferred to a GC/MS device (Thermo Electron Corporation) equipped with a DB-5MS capillary column (J \& W Scientific, Folsom, CA, USA) (60 m×0.25 mm internal diameter, film thickness of $1 \mu \mathrm{m}$ ). GC/MS conditions were a helium carrier gas flow rate of $1.0 \mathrm{~mL} / \mathrm{min}$, an oven temperature program of $40^{\circ} \mathrm{C}$ for 3 min, increased at $5^{\circ} \mathrm{C} / \mathrm{min}$ to $130^{\circ} \mathrm{C}$, increased at $8^{\circ} \mathrm{C} / \mathrm{min}$ to $200^{\circ} \mathrm{C}$, increased at $12^{\circ} \mathrm{C} / \mathrm{min}$ to $250^{\circ} \mathrm{C}$, and kept isothermal for $7 \mathrm{~min}$. The split ratio was 1:10. MS conditions were an ion source temperature of $280^{\circ} \mathrm{C}$, an ionization voltage of $70 \mathrm{eV}$, and a scan range of $\mathrm{m} / \mathrm{z} 30-$ 550 . Volatiles were identified based on comparison of mass spectral data with the NISTDEMO, MAINLIB, WILEY, and REPLIB libraries based on matching of retention indices with reported values and standard alkanes (C6 to C20) (AccuStandard Inc., New Haven, CT, USA) for calculation of Kovats indices (12).

Sensory analysis Selected hams were assessed by a trained panel of 12 members using a quantitative-descriptive analysis method (QDA) (10) for evaluation of the influence of $\mathrm{NaCl}$ replacement with $\mathrm{KCl}$ on sensory characteristics. Panelists were trained and had participated in sensory evaluations of dry-cured hams for 2 years. Individual flavor and aroma recognition thresholds were used as a basis for selection of panelists, who had a total of $120 \mathrm{~h}$ of training in preparation for sensory analysis of ham.

Panel evaluations were held at 11:00 am, $3 \mathrm{~h}$ after breakfast. Three thin slices of $1 \mathrm{~mm}$ corresponding to semimembranosus muscle and Biceps femoris muscles of $8.0 \mathrm{~g}$ each were supplied. Product samples were presented with 3 digit codes in random order. Slices were obtained using a commercial slicing machine and were served immediately on glass plates with both the slices and the plates at room temperature of $20-23^{\circ} \mathrm{C}$. A $100 \mathrm{~mL}$ glass of water at $12^{\circ} \mathrm{C}$ was provided for each panelist between evaluations. All sessions were conducted in a 6 booth sensory panel room at $22^{\circ} \mathrm{C}$ equipped with white fluorescent lighting at 220-230 V and $35 \mathrm{~W}$.

Use of descriptor terms was based on previous reports of drycured ham (10). Eight sensory traits for Jinhua ham grouped as appearance (redness and yellowness), texture (hardness and juiciness), aroma (aroma intensity), and flavor (saltiness, bitterness, and after-taste) were assessed. Each attribute was scored in an unstructured line of $10 \mathrm{~cm}$. Sensory traits, definitions, and extremes were based on the report of Ruiz et al. (14). Sensory evaluation was repeated in 3 sessions carried out on 3 different days. Final scores were averaged over all panelists.

Statistical analysis Five hams were used for each treatment at each sampling time point and each ham was analyzed in triplicate. Data were expressed as mean \pm standard deviation. A factorial analysis of variance (ANOVA) was used for data analysis. Mean values were compared using Duncan's multiple range test and differences were considered significant at $p<0.05$. All statistical analysis was performed using the SPSS ${ }^{\circledR} 19.0$ for Windows (SPSS Inc., Chicago, IL, USA) software package.

\section{Results and Discussion}

Volatile compounds Average amounts of volatile compounds extracted from SM and BF samples treated with either $100 \% \mathrm{NaCl}$ or $60 \% \mathrm{NaCl}$ plus $40 \% \mathrm{KCl}$ at 5 different sampling points are shown in Table 2. Numbers of SM volatile compounds were 51 for formulation 
Table 1. Sampling times, temperature, and relative humidity $(\mathrm{RH})$

\begin{tabular}{|c|c|c|c|c|c|}
\hline Sampling stage & Green ham & End of salting & 30 days of dry-ripening & 60 days of dry-ripening & 100 days of dry-ripening \\
\hline Processing time (day) & 1 & 45 & 79 & 110 & 150 \\
\hline Mean RH (\%) & 79.8 & 75.1 & 55.8 & 53.2 & 55 \\
\hline Highest/lowest RH (\%) & $80.2 / 78.5$ & $85.2 / 74.9$ & $65.2 / 45.3$ & $55.2 / 50.7$ & $55.6 / 53.2$ \\
\hline Mean temp. $\left({ }^{\circ} \mathrm{C}\right)$ & 7.7 & 5.0 & 30.2 & 37.3 & 36.8 \\
\hline Highest/lowest temp. $\left({ }^{\circ} \mathrm{C}\right)$ & $8.5 / 7.0$ & $9.0 / 3.7$ & $32.2 / 26.0$ & $37.8 / 35.3$ & $38.1 / 35.9$ \\
\hline
\end{tabular}

I and 58 for formulation II after 100 days of dry ripening. Numbers of volatile compounds during processing for $\mathrm{BF}$ were 50 for $100 \% \mathrm{NaCl}$ and 48 for $60 \% \mathrm{NaCl}$ plus $40 \% \mathrm{KCl}$ after 100 days of dry-ripening. Identified compounds were categorized into the 10 different chemical families of aldehydes, alcohols, ketones, esters, alkanes, alkenes, sulfur compounds, nitrogenous compounds, chloride compounds, and others.

Most of the volatile compounds identified in this study have been previously identified in dry-cured hams $(7,15)$. The total number of volatiles was similar to a report of Du and Ahn (9) in which 35 compounds were identified and quantified. The number was different from a report of Huan et al. (13) for traditional Jinhua hams, perhaps due to different extraction methods and processing conditions.

Changes in amounts of volatile compounds in Jinhua ham treated with different salt formulations during processing, compared with no processing (green), are shown in Fig. 1 and 2. For the majority of volatile groups, levels increased after processing. Use of formulation II in SM samples resulted in release of more volatile compounds than use of formulation I, while formulation I resulted in more release of the key compounds hexanal and ethanol than formulation II in BF samples.

Aldehydes Aldehydes in dry-cured ham, dry-cured loin, and drycured sausage play vital roles in overall product flavor due to low perception thresholds $(16,17)$, and contribute to the aroma of drycured meat products, even in trace amounts (18). In this study, aldehydes were the second most abundant chemical family in processed Jinhua ham, representing approximately $15 \%$ of the total chromatographic area in SM samples (Fig. $1 \mathrm{~A}$ ) and $45 \%$ in BF samples (Fig. 2A). Much higher relative levels of aldehydes were previously reported for dry-cured meat products (19).

The aldehyde content in Jinhua hams increased significantly $(p<0.05)$ during processing with both salt formulations, compared with controls. Significant $(p<0.05)$ differences in relative levels of aldehydes between the 2 formulations at the end of the salting period were identified. SM samples with both salt formulations and BF samples treated with formulation II exhibited significantly $(p<0.05)$ reduced aldehyde contents at the end of processing, compared with controls, in agreement with a report of Zhang et al. (20) probably due to conversation of aldehydes into other volatile or nonvolatile compounds during dry-ripening.

2-Methylbutanal and 3-methylbutanal, major methyl-branched aldehydes detected in Jinhua hams in this study (Table 2), are products of proteolysis and Strecker degradation of the amino acids isoleucine and leucine (21). Content levels increased during processing time. Levels of 3-methylbutanal in formulation I samples were significantly $(p<0.05)$ higher than in formulation II samples at the end of processing; however, no $(p \geq 0.05)$ significant differences in levels were observed during the first 30 days of dry-ripening stage. Sodium chloride can reportedly greatly restrain proteolytic activity (10). Substitution of $\mathrm{KCl}$ for $\mathrm{NaCl}$ probably enhanced proteolysis and resulted in increased Strecker degradation.

Hexanal was the most abundant straight-chain aliphatic aldehyde identified in dry-cured hams, regardless of salt formulation (Table 2). Hexanal has contributed to rancid odors of foods (22) and is adominant breakdown product of lipid oxidation of $n-6$ fatty acids (15). In this study, the level of hexanal was significantly $(p<0.05)$ higher in hams dry-cured using formulation II than using formulation I, in agreement with a report of Armenteros et al. (23). However, the effect of $\mathrm{KCl}$ substitution was not the same as observed in other hams (8). Replacement of $\mathrm{NaCl}$ with $\mathrm{KCl}$ had a pro-oxidative effect on Jinhua hams in this study, resulting in increased lipid oxidation and formation of lipid-derived volatiles, such as hexanal.

At the end of the dry-ripening phase the hexanal content in ham treated with formulation I was significantly $(p<0.05)$ lower than in ham treated with formulation II, probably due to a reaction between hexanal and amino acids to form Maillard and Strecker compounds (6).

Alcohols Alcohols were the most abundant volatile compounds identified in Jinhua hams (Table 2), representing more than $50 \%$ of volatiles, regardless of sample type and salt formulation, in agreement with other reports (24).

Relative alcohol contents in Jinhua hams treated with the 2 different formulations are shown in Fig. 1B for SM and in Fig. 2B for BF. Alcohol levels increased significantly $(p<0.05)$ during processing, reaching the highest level after 100 days of dry-ripening. Formation and/or release of alcohols were significantly affected by salt formulations at the beginning of processing. However, no significant $(p>0.05)$ differences were found at the end of processing for formation and/or release of alcohols between the 2 formulations.

Ethanol, which is likely produced during carbohydrate fermentation by microorganisms (7), accounted for more than $30 \%$ of the total volatile fraction at the end of processing, in agreement with a previous report (25). The ethanol content was only $0.38 \%$ of total 


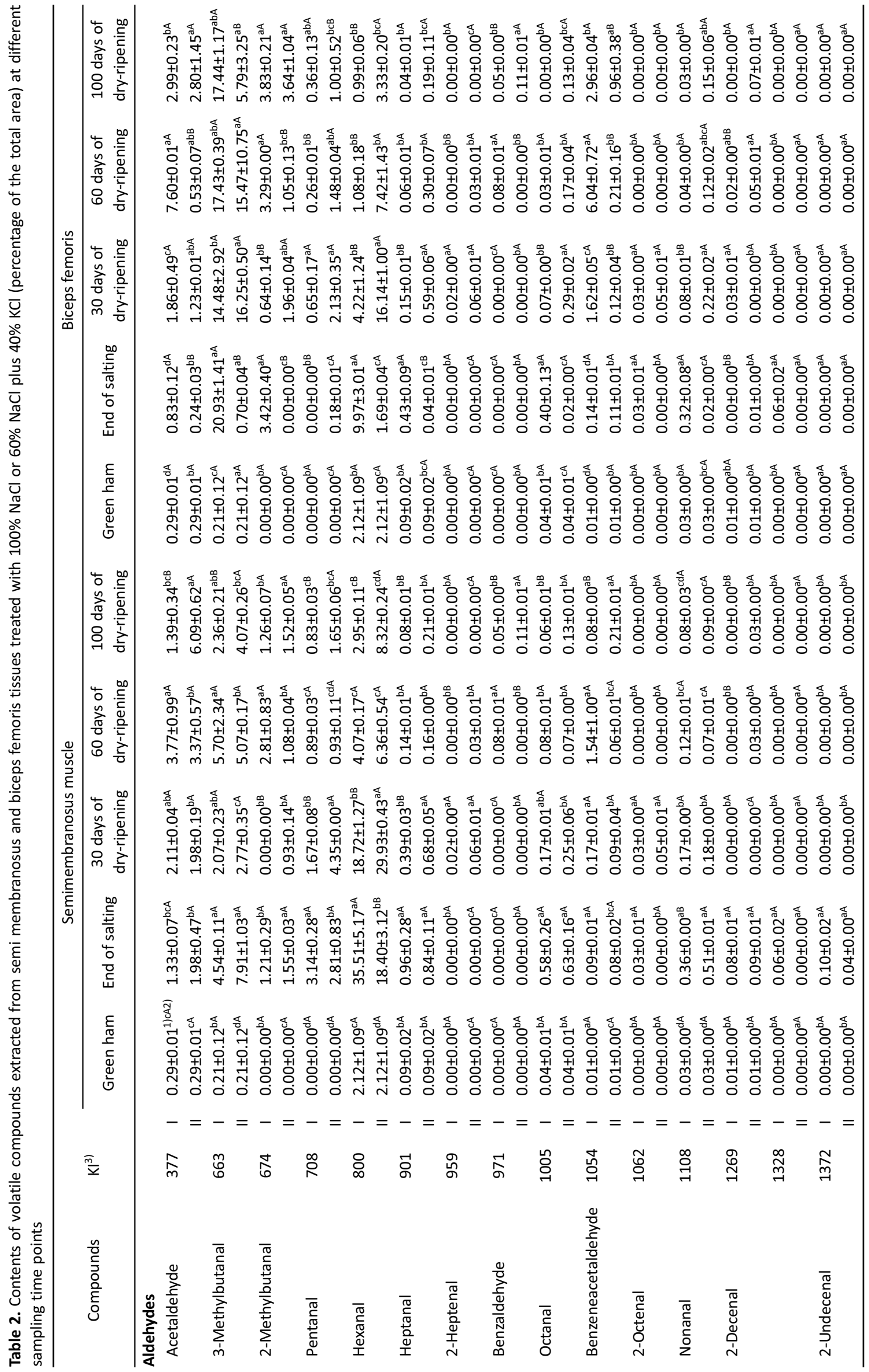




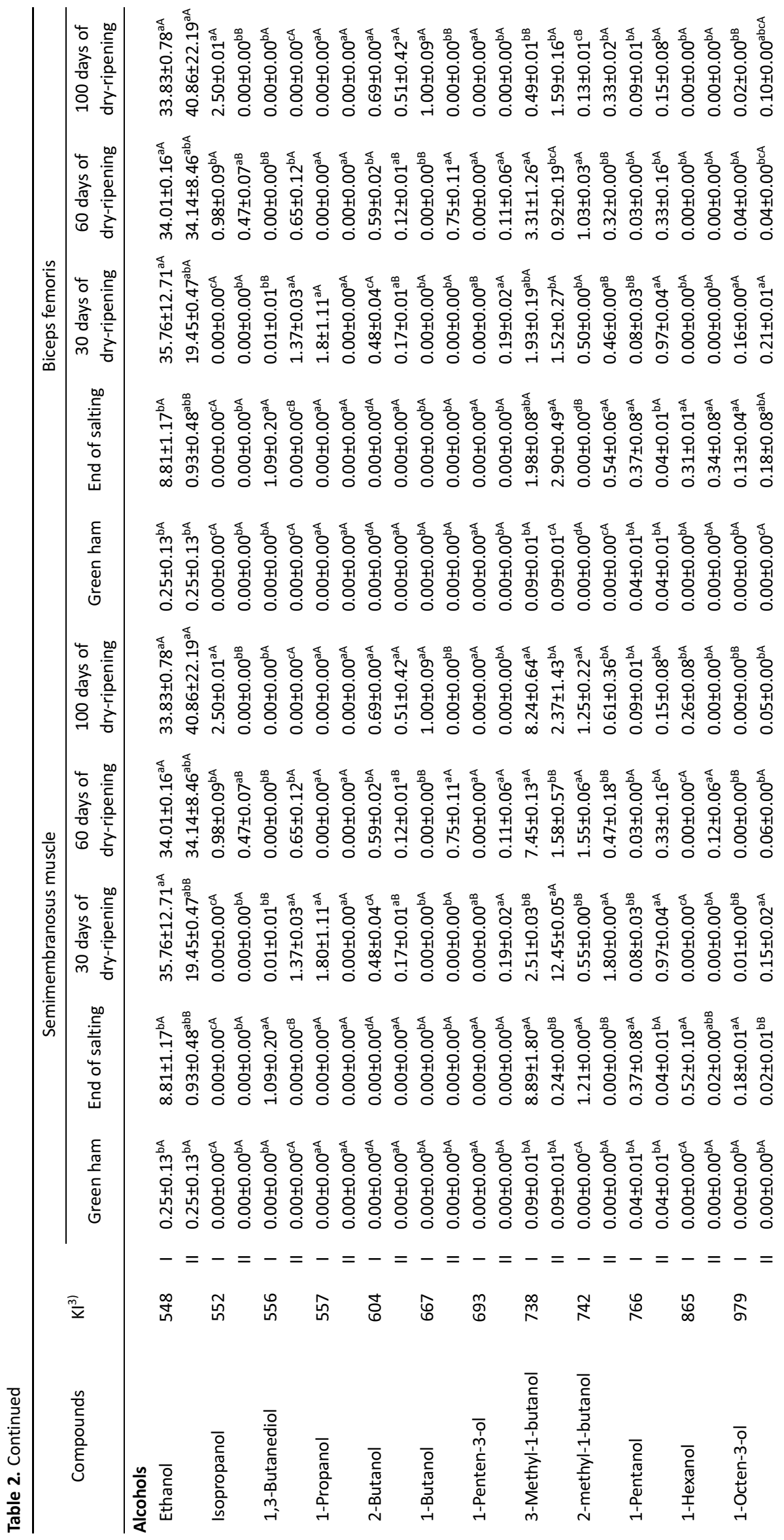

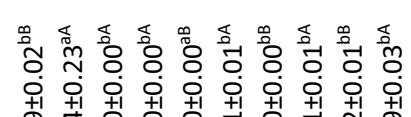

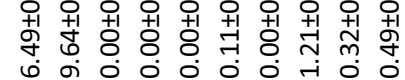

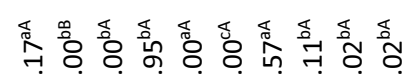

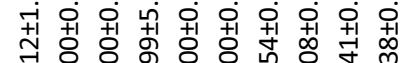

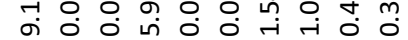

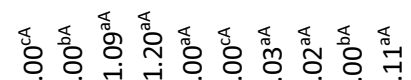

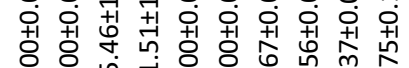

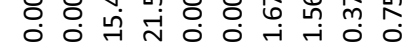

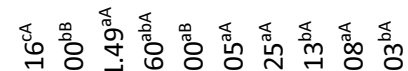

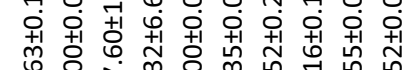

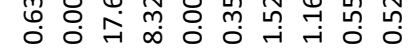

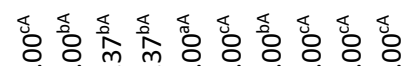

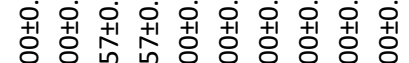

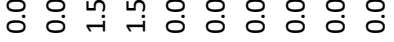

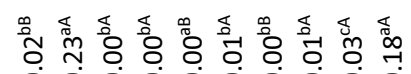

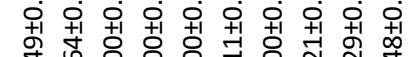
迥

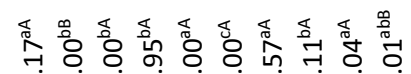

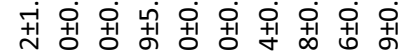

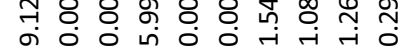

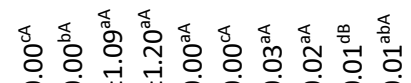

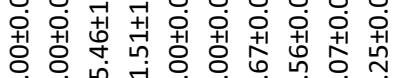

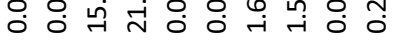

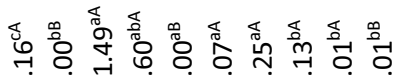

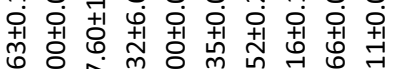
过定

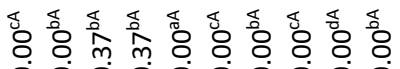

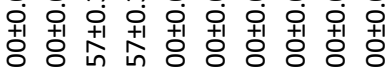

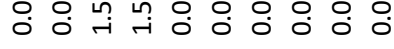
$-=-=-=-=$

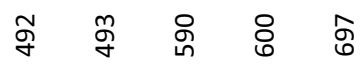

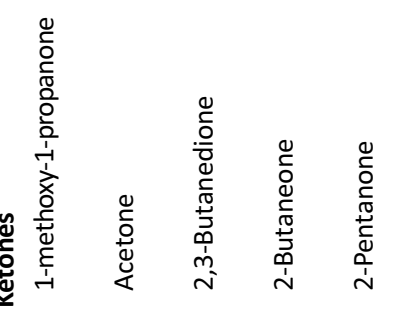




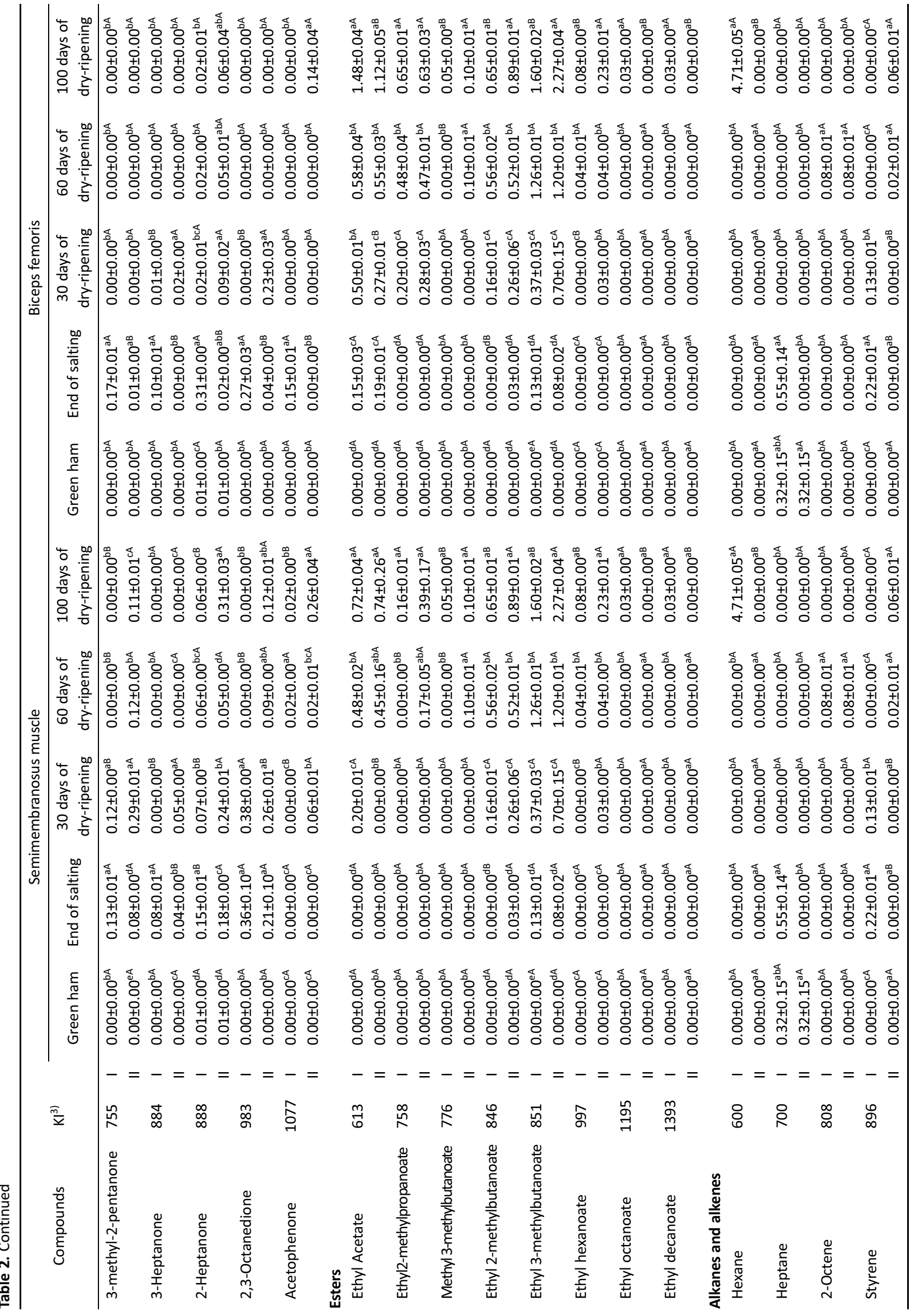

Food Sci. Biotechnol. 







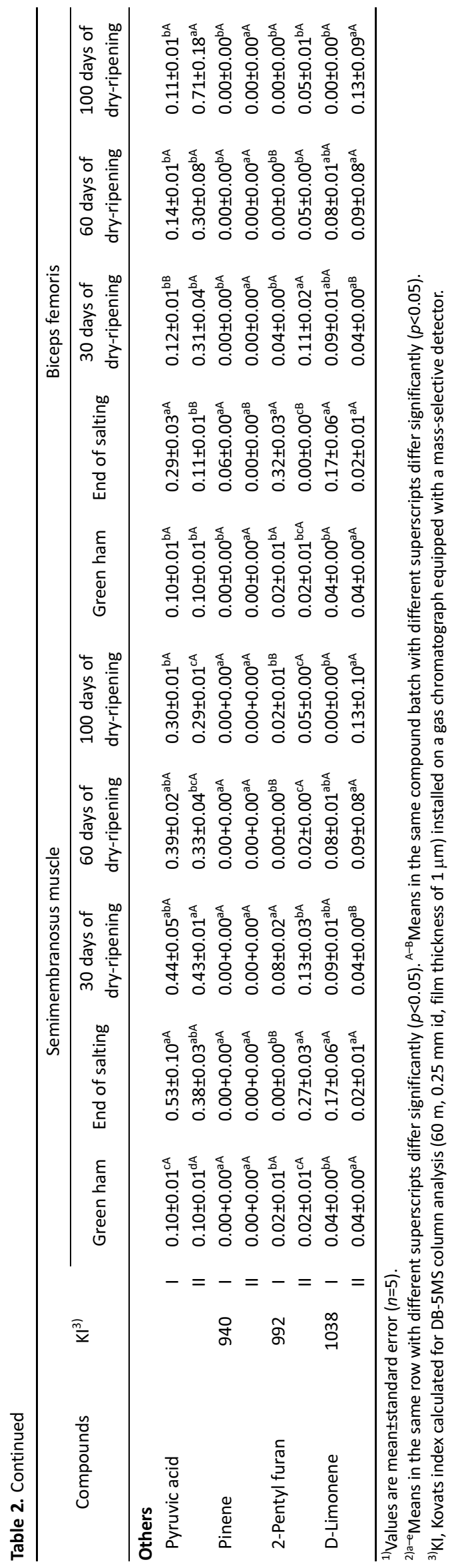


volatiles in green ham and the high ethanol content in ham products was most likely due to processing. There was a significant $(p<0.05)$ difference in ethanol contents between the 2 salt formulations at the end of both the salting and ripening stages for SM, and only at the end of the salting stage for BF samples. Hams salted with formulation II showed significantly $(p<0.05)$ higher levels of ethanol than hams salted with formulation I. Partial replacement of $\mathrm{NaCl}$ with $\mathrm{KCl}$ probably enhanced microbial growth and generated more ethanol, which contributed little to the overall flavor of dry-cured ham because of a high odor threshold value (25).

2-Methylbutanol and 3-methylbutanol, derivatives of 2-methylbutanal and 3-methylbutanal reduction, respectively (24), are probably important volatile compounds of dry-cured ham due to relatively low odor threshold values (24). Compared with formulation I, treatment with formulation $\|$ resulted in significantly $(p<0.05)$ increased formation of these 2 methyl alcohols. Thus, $\mathrm{KCl}$ substitution had a significant $(p<0.05)$ effect for increasing formation of 2methylbutanol and 3-methylbutanol, compared with controls (Table 2). However, a significant $(p>0.05)$ difference was not observed for BF samples, compared with controls, probably due to reduced levels of chemical reduction of corresponding branched aldehydes by microbial enzymes because of low microbial counts in hams, conditions that are unfavorable for microbial growth, resulting in (26) low microbial enzyme activity levels (27).

The secondary alcohol 1-octen-3-ol derived from linoleic acid oxidation provided a mushroom note $(25,28)$. For SM samples, no significant ( $p \geq 0.05$ ) difference was found during processing between the 2 salt formulations, except at the end of processing. However, for BF samples, formulation II significantly $(p<0.05)$ increased formation of 1-octen-3-ol during processing, compared with controls. Thus, $\mathrm{NaCl}$ may not have exerted a salting out effect due to release 1octen-3-ol, as reported by Flores et al. (19) for Spanish Serranot drycured hams.

Ketones Ketone contents increased significantly $(p<0.05)$ after salting, compared with controls (Fig. $1 \mathrm{C}$ and $2 \mathrm{C}$ ), similar to a previous report (9). Nevertheless, variation in ketone contents between the 2 different salt formulations was observed during processing (Table 2). The maximum percentage of total ketones appeared at the end of the salting stage for formulation I, while the highest level was reached after 30 days of dry-ripening for formulation 2 . Nine ketones were identified, including 2-pentanone, 2-hexanone, 2-heptanone, 2,3-butanedione, 2,3-octanedione, and acetone, which was the most common ketone identified in this study. Hams salted with formulation II produced significantly $(p<0.05)$ more ketones, compared with controls. 2-Ketones are considered to have a great effect on meat (22) and are believed to be products of autoxidation or $\beta$-oxidation of fatty acids (29). Replacement of $\mathrm{NaCl}$ with $\mathrm{KCl}$ apparently promoted oxidation of fatty acids.

Esters Changes in ester levels during ham processing are shown in
Fig. 1D and 2D. Effects of both salt formulations on ester contents in SM samples were significant $(p<0.05)$ for all processing times. No significant $(p>0.05)$ difference was observed in BF samples until the final stage of dry-ripening. No esters were detected in green hams. Differences between the 2 sample types may have been due to differences in penetration speeds of different salts, which affected formation of volatile compounds during processing (23). Ethyl 2methylbutanoate accounted for most esters in Jinhua hams (13), the content of which in hams salted with formulation II was significantly $(p<0.05)$ higher than in hams salted using formulation I. The same relationship was observed for the ethyl 3-methylbutanoate content. Substitution of $\mathrm{KCl}$ for $\mathrm{NaCl}$ in hams might have accelerated proteolysis (6), generated more alcohols, and formed more esters in reactions with free fatty acids. The esters ethyl 2-methylbutanoate and ethyl acetate were also identified in cured hams $(13,15)$. Ethylesters were formed by combination of ethyl alcohol and acids during processing (16). Formation of methyl-branched, short-chain esters was found to be positively related to aging of meat (30).

Alkanes and alkenes Changes in formation of alkanes and alkenes in processed hams during processing are shown in Fig. $1 \mathrm{E}$ and $2 \mathrm{E}$. Levels of alkanes and alkenes increased significantly $(p<0.05)$ in processed hams using both formulations, compared with controls, by the end of the salting period. However, a sharp decrease was observed in BF samples during the ripening stage for both salt formulations. On the contrary, alkane levels significantly $(p<0.05)$ increased during processing in SM samples using formulation II, compared with controls. However, with formulation I, alkane levels first decreased, then sharply increased at the end of dry-ripening, perhaps attributable to differences in degradation and intermolecular rearrangement of fatty acids and amino acids in different ham parts (9). Since alkanes and alkenes have relatively high odor threshold levels, both have almost no contribution to overall aromas of drycured hams (31).

Sulfur compounds Sulfur compounds mainly originate from methionine, cysteine, and cystine via Strecker degradation of thiols (20). Changes in levels of volatile sulfur compounds during Jinhua ham processing are shown in Fig. $1 \mathrm{~F}$ and $2 \mathrm{~F}$. The 4 sulfur compounds identified in this study were methanethiol, dimethyl disulfide, dimethyl trisulfide, and benzothiazole, in agreement with results reported by Huan et al. (13). Both salting formulations affected the content of methanethiol in BF samples during dry-ripening. Hams treated with $100 \% \mathrm{NaCl}$ exhibited a significantly $(p<0.05)$ higher methanethiol content, compared with controls. Relatively low sulfur compound levels provided important contributions to the overall flavor of hams because of low threshold values, lower than for other volatile compounds.

Nitrogenous compounds Only trace levels of nitrogenous compounds were detected throughout processing (Fig. 1G and 2G). A continued 

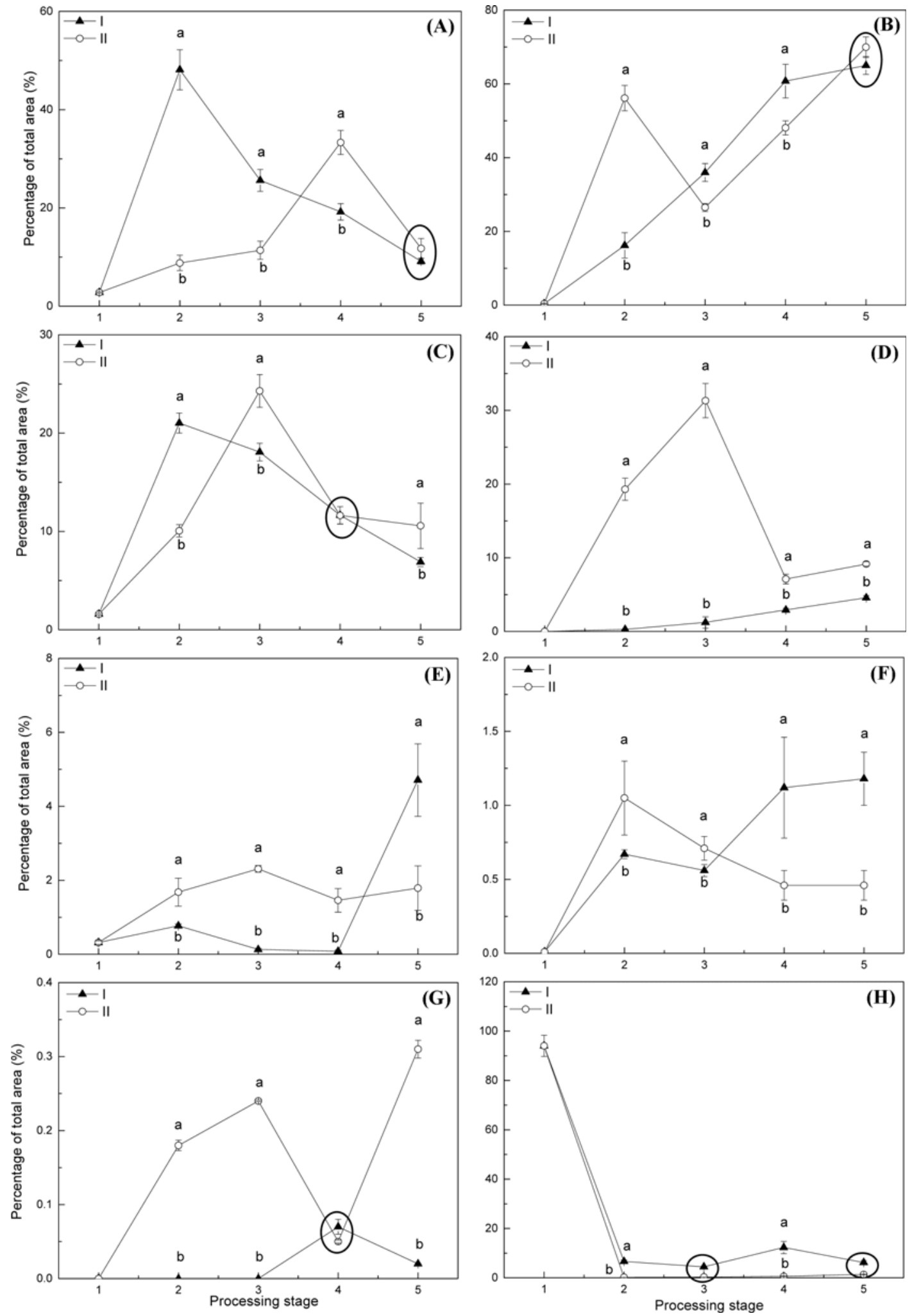

Fig. 1. Evolution of volatile compounds (A, Aldehydes; B, Alcohols; C, Ketones; D, Esters; E, Alkanes and alkenes; F, Sulfur compounds; G, Nitrogenous compounds; $\mathrm{H}$, Chloride compounds) in semi membranosus muscle tissues during Jinhua ham processing. ( $\mathbf{\Delta}$ ) Formulation I of $100 \%$ $\mathrm{NaCl}$, and $(\bigcirc)$ formulation II of $60 \% \mathrm{NaCl}$ and $40 \% \mathrm{KCl}$. Error bars indicate standard error for each mean value. Different letters indicate significant differences between the 2 salt formulations $(p<0.05)$. 

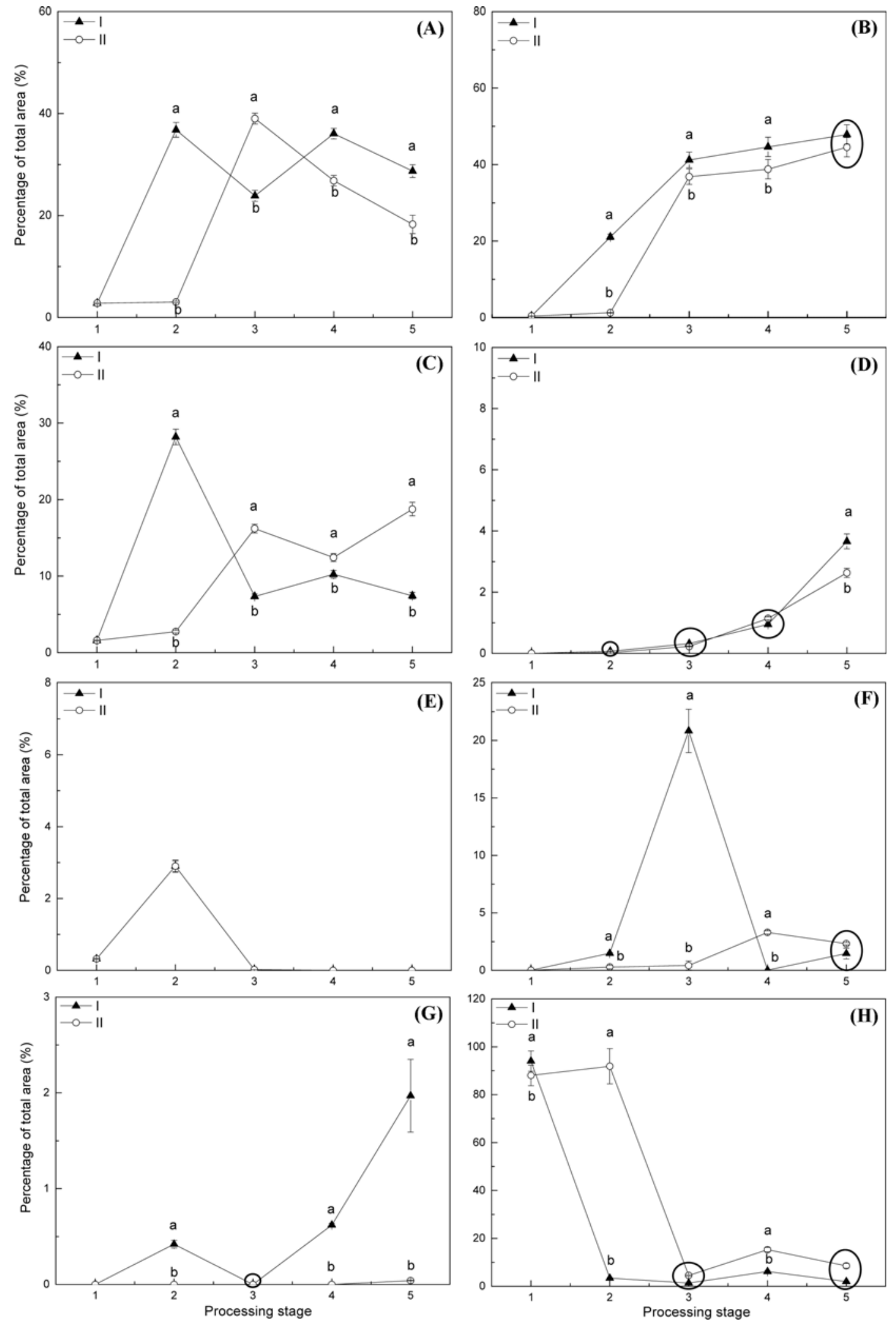

Fig. 2. Evolution of volatile compounds (A, Aldehydes; B, Alcohols; C, Ketones; D, Esters; E, Alkanes and alkenes; F, Sulfur compounds; G, Nitrogenous compounds; $\mathrm{H}$, Chloride compounds) in Biceps femorismuscle tissues during Jinhua ham processing, ( $\mathbf{\Delta}$ ) formulation I of $100 \% \mathrm{NaCl}$, and $(O)$ formulation II of $60 \% \mathrm{NaCl}$ and $40 \% \mathrm{KCl}$. Error bars indicate standard error for each mean value. Different letters indicate significant differences between the 2 salt formulations $(p<0.05)$. 
Table 3. Mean values of sensory traits of semi membranosus and biceps femoris muscle tissues from Jinhua hams prepared using different salt formulations: I: Control, $100 \% \mathrm{NaCl}$; II: $60 \% \mathrm{NaCl}$ and $40 \% \mathrm{KCl}$

\begin{tabular}{|c|c|c|c|c|}
\hline \multirow{2}{*}{ Sensory traits } & \multicolumn{2}{|c|}{ Semimembranosus } & \multicolumn{2}{|c|}{ Biceps femoris } \\
\hline & I & II & I & II \\
\hline Redness & $6.24 \pm 0.85^{\mathrm{a} 1)}$ & $6.01 \pm 0.32^{\mathrm{a}}$ & $5.81 \pm 0.41^{\mathrm{A} 2)}$ & $5.31 \pm 0.29^{A}$ \\
\hline Yellowness & $3.03 \pm 0.45^{\mathrm{a}}$ & $3.01 \pm 0.11^{\mathrm{a}}$ & $3.12 \pm 0.27^{A}$ & $3.22 \pm 0.09^{A}$ \\
\hline Hardness & $5.45 \pm 0.29^{\mathrm{a}}$ & $5.85 \pm 0.46^{\mathrm{a}}$ & $4.44 \pm 0.37^{\mathrm{A}}$ & $4.87 \pm 0.22^{\mathrm{A}}$ \\
\hline Juiciness & $4.41 \pm 0.31^{\mathrm{a}}$ & $4.25 \pm 0.26^{\mathrm{a}}$ & $5.33 \pm 0.16^{A}$ & $5.31 \pm 0.30^{\mathrm{A}}$ \\
\hline Aroma intensity & $4.59 \pm 0.23^{a}$ & $4.14 \pm 0.31^{a}$ & $4.64 \pm 0.24^{\mathrm{A}}$ & $4.35 \pm 0.45^{\mathrm{A}}$ \\
\hline Saltiness & $5.09 \pm 0.27^{\mathrm{a}}$ & $4.01 \pm 0.41^{b}$ & $5.72 \pm 0.43^{A}$ & $4.60 \pm 0.35^{B}$ \\
\hline Bitterness & $1.10 \pm 0.22^{\mathrm{a}}$ & $1.14 \pm 0.29^{\mathrm{a}}$ & $1.29 \pm 0.37^{A}$ & $1.28 \pm 0.46^{\mathrm{A}}$ \\
\hline After-taste & $4.55 \pm 0.21^{\mathrm{a}}$ & $4.24 \pm 0.33^{a}$ & $4.65 \pm 0.44^{A}$ & $4.48 \pm 0.22^{\mathrm{A}}$ \\
\hline
\end{tabular}

1)a-b: Means in the same row with different superscripts differ significantly for Semimembranosus $(p<0.05)(n=30)$.

${ }^{2)} A-B$ : Means in the same row with different superscripts differ significantly for Biceps femoris $(p<0.05)(n=30)$.

significant $(p<0.05)$ increase in nitrogenous compound levels was detected in Jinhua ham throughout processing, compared with controls. Generally, pyrazineisa typical product of Maillard reactions during meat cooking (13). Numbers and content levels of nitrogenous compounds in this study were lower than reported by Huan et al. (13), probably due to a relative short ripening time in this study, compared with traditional Jinhua ham processing of approximately 300 ripening days. In this study, the nitrogenous compounds trimethylamine and dimethylamine were identified in cured BF samples, which were not previously reported (25). There was no significant $(p \geq 0.05)$ difference in formation of 2,4-dimethyl pyrimidine between the 2 salt formulations and also during processing (Table 2).

Chloride compounds Changes in chloride compound levels during processing are shown in Fig. $1 \mathrm{H}$ and $2 \mathrm{H}$. Methylene chloride, a major volatile chloride compound, was only found in green ham. Du and Ahn (9) concluded that chloride volatiles in hams did not originate from meat products but did originate from packaging materials or from pesticide residues ingested by pigs.

Others 2-Pentyl-furan, which is supposedly an oxidation product of linoleic acid, is usually found in dry-cured hams (19). In this study, use of formulation II resulted in significantly $(p<0.05)$ higher levels of 2 pentyl furan in Jinhua hams than use of formulation $\mathrm{I}$, in agreement with the aforementioned results for 1-octen-3-ol, which is also considered to be a derivative of linoleic acid oxidation.

Sensory analysis Sensory analytical study of dry-cured hams salted using the 2 formulations are shown in Table 3. Substitution of $\mathrm{KCl}$ for $\mathrm{NaCl}$ did not significantly ( $p>0.05$ ) affected any sensory characteristics for both SM and BF samples, compared with controls, except saltiness. This implies that a significant affect was in disagreement with a report of Armentero et al. (32) that replacement of $\mathrm{NaCl}$ with up to $50 \% \mathrm{KCl}$ did not affect sensory attributes (32). Replacement of $\mathrm{NaCl}$ with $40 \% \mathrm{KCl}$ probably resulted in a reduced salty dry-cured ham taste that was evaluated positively by assessors (26). Moreover, salt is not the only factor determining a salty taste, which can also be influenced by amino acids and nucleotides (16).

In conclusion, $40 \%$ replacement of $\mathrm{NaCl}$ with $\mathrm{KCl}$ had an influence on formation of volatile compounds throughout processing of drycured hams in both SM and BF muscle tissues. Increased formation and/or release of volatile compounds was observed during Jinhua ham processing, particularly during salting and the first ripening stage. The most pronounced differences were detected at the end of the salting phase. Formulation II of $60 \% \mathrm{NaCl}$ and $40 \% \mathrm{KCl}$ promoted formation of lipid-derived aldehydes, Strecker aldehydes, alcohols, and methyl-branched aldehydes from amino acids. Thus, replacement of $\mathrm{NaCl}$ with $40 \% \mathrm{KCl}$ influenced the aroma of Jinhua ham. However, sensory analysis of final products indicated that it was possible to reduce the $\mathrm{NaCl}$ content by $40 \%$ in dry-cured ham without adverse effects on sensory properties to satisfy consumer demands and health requirements. Confirmation of whether partial replacement of $\mathrm{NaCl}$ with $\mathrm{KCl}$ will affect the safety and overall acceptability of final products will require further study.

Acknowledgments This work was supported by Agro-Scientific Research in the Public Interest (201303082-2) and the Huaian Science and Technology Project (HAN2014030).

Disclosure The authors declare no conflict of interest.

\section{References}

1. Armenteros M, Aristoy MC, Barat JM, Toldra F. Biochemical and sensory changes in dry-cured ham salted with partial replacements of $\mathrm{NaCl}$ by other chloride salts. Meat Sci. 90: 361-367 (2012)

2. Desmond E. Reducing salt: A challenge for the meat industry. Meat Sci. 74: 188-196 (2006)

3. McCarty MF. Should we restrict chloride rather than sodium? Med. Hypotheses 63: 138-148 (2004)

4. Gelabert J, Gou P, Guerrero L, Arnau J. Effect of sodium chloride replacement on some characteristics of fermented sausages. Meat Sci. 65: 833-839 (2003)

5. Alino M, Grau R, Toldra F, Blesa E, Pagan MJ, Barat JM. Influence of sodium replacement on physicochemical properties of dry-cured loin. Meat Sci. 83: 423-430 (2009) 
6. Barbieri G, Bolzoni L, Parolari G, Virgili R, Buttini R, Careri M, Mangia A. Flavor compounds of dry-cured ham. J. Agr. Food Chem. 40: 2389-2394 (1992)

7. Garcia C, Berdague JJ, Antequera T, Lopezbote C, Cordoba JJ, Ventanas J. Volatile components of dry cured Iberian ham. Food Chem. 41: 23-32 (1991)

8. Andres A I, Cava R, Ventanas J, Muriel E, Ruiz J. Lipid oxidative changes throughout the ripening of dry-cured Iberian hams with different salt contents and processing conditions. Food Chem. 84: 375-381 (2004)

9. Du M, Ahn DU. Volatile substances of Chinese traditional Jinhua ham and Cantonese sausage. J. Food Sci. 66: 827-831 (2001)

10. Zhang J, Wang L, Liu Y, Zhu J, Zhou G. Changes in the volatile flavor components of Jinhua ham during the traditional ageing process. Int. J. Food Sci. Tech. 41: 1033-1039 (2006)

11. Wu H, Zhang Y, Long M, Tang J, Yu X, Wang J, Zhang J. Proteolysis and sensory properties of dry-cured bacon as affected by the partial substitution of sodium chloride with potassium chloride. Meat Sci. 96: 1325-1331 (2014)

12. Wu $\mathrm{H}$, Zhuang $\mathrm{H}$, Zhang $\mathrm{Y}$, Tang J, $\mathrm{Yu} X$, Long $M$, Zhang J. Influence of partial replacement of $\mathrm{NaCl}$ with $\mathrm{KCl}$ on profiles of volatile compounds in dry-cured bacon during processing. Food Chem. 172: 391-399 (2015)

13. Huan YJ, Zhou GH, Zhao GM, Xu XL, Peng ZQ. Changes in flavor compounds of dry-cured Chinese Jinhua ham during processing. Meat Sci. 71: 291-299 (2005)

14. Ruiz J, Garcia C, Muriel E, Andrés A, Ventanas J. Influence of sensory characteristics on the acceptability of dry-cured ham. Meat Sci. 61: 347-354 (2002)

15. Dirinck $P$, VanOpstaele $F$, Vandedriessche F. Flavor differences between northern and southern European cured hams. Food Chem. 59: 511-521 (1997)

16. Careri M, Mangia A, Barbieri G, Bolzoni L, Virgili R, Parolari G. Sensory property relationships to chemical-data of Italian-type dry-cured ham. J. Food Sci. 58: 968-972 (1993)

17. Hinrichsen LL, Pedersen SB. Relationship among flavor, volatile compounds, chemical-changes, and microflora in Italian-type dry-cured ham during processing. J. Agr. Food Chem. 43: 2932-2940 (1995)

18. Montel MC, Reitz J, Talon R, Berdague JL, Rousset-Akrim S. Biochemical activities of micrococcaceae and their effects on the aromatic profiles and odours of a dry sausage model. Food Microbiol. 13: 489-499 (1996)

19. Flores M, Grimm CC, Toldra F, Spanier AM. Correlations of sensory and volatile compounds of Spanish "Serrano" dry-cured ham as a function of two processing times. J. Agr. Food Chem. 45: 2178-2186 (1997)

20. Zhang J, Jin G, Wang J, Zhang W. Effect of intensifying high-temperature ripening on lipolysis and lipid oxidation of Jinhua ham. Food Sci. Technol. 44: 473-479 (2011)

21. Hidalgo FJ, Zamora R. Strecker-type degradation produced by the lipid oxidation products 4,5-epoxy-2-alkenals. J. Agr. Food Chem. 52: 7126-7131 (2004)

22. Gaspardo B, Procida G, Toso B, Stefanon B. Determination of volatile compounds in San Daniele ham using headspace GC-MS. Meat Sci. 80: 204209 (2008)

23. Armenteros M, Toldra F, Aristoy MC, Ventanas J, Estevez M. Effect of the partial replacement of sodium chloride by other salts on the formation of volatile compounds during ripening of dry-cured ham. J. Agr. Food Chem. 60: 7607-7615 (2012)

24. Wang J, Jin G, Zhang W, Ahn D, Zhang J. Effect of curing salt content on lipid oxidation and volatile flavor compounds of dry-cured turkey ham. Food Sci. Technol. 48: 102-106 (2012)

25. Garcia-Gonzalez DL, Tena N, Aparicio-Ruiz R, Morales MT. Relationship between sensory attributes and volatile compounds qualifying dry-cured hams. Meat Sci. 80: 315-325 (2008)

26. Arnau J, Guerrero L, Sárraga C. The effect of green ham $\mathrm{pH}$ and $\mathrm{NaCl}$ concentration on cathepsin activities and the sensory characteristics of drycured hams. J. Sci. Food Agr. 77: 387-392 (1998)

27. Barcarolo R, Casson P, Tutta C. Analysis of the volatile constituents of food by headspace GC-MS with reversal of the carrier gas flow during sampling. J. High Res. Chromatog. 15: 307-311 (1992)

28. Andres Al, Cava R, Ventanas S, Muriel E, Ruiz J. Effect of salt content and processing conditions on volatile compounds formation throughout the ripening of Iberian ham. Eur. Food Res. Technol. 225: 677-684 (2007)

29. Ganzle MG, Vermeulen N, Vogel RF. Carbohydrate, peptide and lipid metabolism of lactic acid bacteria in sourdough. Food Microbiol. 24: 128-138 (2007)

30. Jurado A, Carrapiso Al, Ventanas J, Garcia C. Changes in SPME-extracted volatile compounds from Iberian ham during ripening. Grasas Aceites 60: 262270 (2009)

31. Drumm TD, Spanier AM. Changes in the content of lipid autoxidation and sulfur-containing-compounds in cooked beef during storage. J. Agr. Food Chem. 39: 336-343 (1991)

32. Armenteros M, Aristoy MC, Barat JM, Toldra F. Biochemical and sensory properties of dry-cured loins as affected by partial replacement of sodium by potassium, calcium, and magnesium. J. Agr. Food Chem. 57: 9699-9705 (2009) 